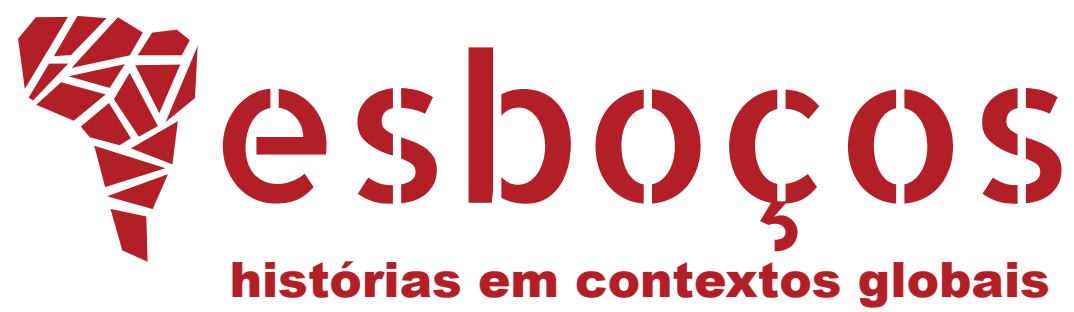

\title{
A UNIDADE POLÍTICO-RELIGIOSA E A QUESTÃO JUDAICA NA ÓTICA DE ISIDORO DE SEVILHA
}

The Political-Religious Union and the Jewish Question on Isidore of Seville's Perspective

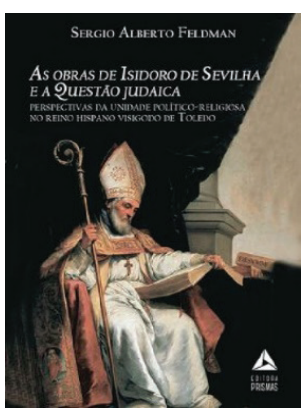

FELDMAN, Sergio Alberto. As obras de Isidoro de Sevilha e a questão judaica: perspectivas da unidade político-religiosa no reino hispano visigodo de Toledo. Curitiba: Prismas, 2017. 308p.

\section{PALAVRAS-CHAVE}

Isidoro de Sevilha. Judaísmo. Cristianismo.

\section{KEYWORDS}

Isidore of Seville. Judaism. Christianity. 
$\mathbf{N}$ a busca pela compreensão de um período histórico limítrofe e no desvelar de seus valores políticos e religiosos, torna-se necessário lançar mão de fontes históricas à luz da mesma época. Tal apreensão se avoluma quando temos como ponto de partida os escritos de uma personalidade marcante para sua época e para tempos vindouros, posto que acaba por representar um ideal de sociedade. Assim, As obras de Isidoro de Sevilha e a questão judaica: perspectivas da unidade político-religiosa no reino hispano visigodo de Toledo, de Sergio Feldman, traz Isidoro de Sevilha como seu marco de reflexão, especialmente por ele ter empreitado a unidade política, religiosa e social no reino hispano-visigodo de Toledo, as relações no âmbito do poder temporal e clerical e o conflito entre cristianismo e judaísmo no século VII.

Fruto de seu doutoramento, o livro propõe a discussão acerca da relação entre monarquia visigótica e seus súditos judeus. Ao longo da obra, o autor chama a atenção para o conflito teológico com o judaísmo desenvolvido pelos primeiros padres da Igreja e como esses, sobretudo Agostinho de Hipona, influenciam aspectos da visão de mundo isidoriana. Todavia, não perde de vista que o judeu tinha um importante papel na escatologia cristã. Dessa forma, como lidar com as minorias judaicas presentes no reino? Mais do que isso, como tolerar e explicar a funcionalidade judaica em meio a políticas reprimendas, uma vez que a política bebia do fundamento religioso? Essas questões são vigas mestras da obra e revisitadas em todos os capítulos.

A pertinência e a contribuição da obra aqui resenhada também reside nas reflexões acerca dos judeus e do judaísmo na história. Em outras palavras, percebe, na longa duração, como o judeu é alvo de pressões e abusos em sociedades não judaicas. Tendo isso se tornado um ciclo repetitivo que extrapolou questões de ordem política ou religiosa, vemos razões socioeconômicas e raciais inseridas e/ou camufladas. Por essa fenda interpretativa, o trabalho de Sergio Feldman dialoga e critica uma vasta historiografia espanhola e francesa a respeito da unidade político-religiosa no reino visigodo de Toledo, porém com o foco recaindo sobre a questão judaica. $\mathrm{O}$ autor se ampara em alguns trabalhos clássicos e outros de ordem mais factual, como os de Pidal. Clássicos como Orlandis e Garcia Moreno introduziram o autor no contexto da sacralização da monarquia visigótica e no sistema administrativo daquelas instituições. Outros muitos autores, como Marc Reydellet e J. Fontaine, permitiram a Feldman compreender o projeto educacional isidoriano, atentando para contradições presentes na historiografia ainda sem respostas, mas a respeito das quais a presente obra não hesita em se posicionar ou mesmo propor outro viés interpretativo.

Por esse ângulo, a historiografia brasileira se serve de bons trabalhos acerca da monarquia visigoda no âmbito da Antiguidade tardia, como os de Ruy O. Andrade Filho sobre as relações entre religião e religiosidade, com especial enfoque na "analogia antropomórfica" e na conversão visigoda ao catolicismo. Renan Frighetto também tem inúmeras contribuições sobre a Antiguidade tardia, tendo como relevo a monarquia hispano-visigoda e suas múltiplas relações políticas. Além desses, poderíamos citar uma miríade de autores brasileiros que fomentam e alicerçam os estudos sobre a monarquia visigoda, mas ainda assim deixaríamos de fora importantes contribuições. No entanto, o livro aqui resenhado guarda singularidades e contribuições pertinentes a essa discussão, posto que lança luz a novos vieses interpretativos por meio das obras isidorianas, sobretudo com foco na questão judaica.

Assim, o primeiro capítulo, "Reflexões iniciais", reúne uma avaliação crítica da produção historiográfica acerca dos judeus e do judaísmo desde os tempos de Roma, demonstrando os entraves já presentes entre judeus e romanos, algo que pioraria 
com o florescimento do cristianismo e a conversão do Império. Discutindo, nesse primeiro momento, a ótica dos primeiros padres sobre os judeus, Feldman entende que o ódio e o desprezo aos judeus foram instituídos com o intento de separar as duas comunidades e criar uma identidade cristã. Além disso, a interpretação sobre como o cristianismo católico se firma ao longo da história com uma de suas bases repousadas na exclusão das minorias judaicas é colocada em relevo pelo autor.

No segundo capítulo, "A monarquia hispano-visigótica: a busca da unidade e da legitimidade", o autor discorre sobre o estabelecimento dos visigodos na Hispânia e suas relações com o Império Romano, porém o enfoque está em compreender os modus como se definiam os reis e como o processo de destribalização do poder ocorreu. Segundo ele, de maneira lenta e gradual, moldando uma nova sociedade que, a passos lentos, via a centralização do poder e futura monarquia, em especial com uma dicotomia jurídica e religiosa que dividia tal sociedade. Os visigodos tinham leis próprias, mas isso se alterou gradualmente, com a população passando a ser regida pelo códex Theodosianus. No entanto, graças às necessidades, Alarico editou algumas leis retiradas do códex, formando o breviário de Alarico. Feldman afirma que ele é o primeiro rei visigodo a editar leis aos judeus. Assim, destaca os debates historiográficos quanto à postura dos reis visigodos arianos em relação aos judeus. Feldman se aproxima da interpretação de que os monarcas não convertiam os judeus à força. $O$ autor está preocupado em compreender o que as fontes jurídicas nos dão a entender sobre as relações cotidianas entre judeus e cristãos, além da visão do povo e do clero sobre eles.

O autor demonstra como o início do século VI é um período de crise para a monarquia, em que ocorreram constantes conflitos entre poder monárquico e a nobreza proprietária de terras. Afim de analisar o reinado de Leovigildo, Feldman lança mão dos escritos de João de Bíclaro, pois realiza paralelos entre Império e o reino visigodo. Gregório de Magno e Gregório de Tours também são utilizados nessa empreitada de compreender traços da política monárquica. Feldman ainda analisa a contradição religiosa de nobreza ariana e povo católico vivendo num mesmo espaço - Leovigildo buscou diminuir as diferenças religiosas, porém enfrentou sublevações. A ascensão de Recaredo, convertido ao catolicismo niceno, levou consigo o alto clero ariano e nobres visigodos, firmando um "pacto social e religioso".

Esse pacto, mais tarde, geraria conflitos e acabaria com a aceitação de muitos arianos ao catolicismo. Recaredo consegue a união com a igreja e solidifica a proposta de seu pai, ainda que judeus, heréticos e pagãos tenham ficado fora dos planos. Feldman chama a atenção para os limites do poder da monarquia, uma vez que a nobreza e a Igreja eram influentes. Isidoro de Sevilha é basilar na defesa dos valores cristãos, e os judeus se tornam um desafio - as leis destinadas a eles ultrapassavam às do paganismo, e a questão judaica chegou aos concílios.

O reinado de Sisebuto, entretanto, se tornou "um marco nas relações entre a monarquia e o clero com a população judaica do reino hispano-visigodo. Nele ocorre a conversão forçada da comunidade judaica, em especial daquela localizada em Toledo" (FELDMAN, 2017, p. 109). Sisebuto colocou pressão direta pela conversão. Feldman rebate outros autores que afirmam que tais decisões foram econômicas. Ele entende que a motivação religiosa foi maior, e as entrelinhas dos decretos econômicos, políticos e militares desvelaram fatores religiosos, sobretudo a relação implícita entre jurídico-política e religião. O autor alerta que a postura de conversão forçada teve oposição de setores da nobreza e da Igreja, posto que ia de encontro com seus entendimentos de conversão. 
Feldman afirma que, mesmo Isidoro não concordando com os meios, concordava com os fins, uma vez que a conversão dos judeus era um projeto cristão. $\mathrm{O}$ autor chega a ratificar que Isidoro teria tido influência nas conversões forçadas por sua proximidade com o rei. Todavia, estava evidente que o projeto era guardar a fé niceísta, algo que Isidoro faria com ênfase no século VII.

Nesse viés, o terceiro capítulo, o mais extenso do livro, "Isidoro de Sevilha: construtor teórico da unidade sociorreligiosa do reino hispano-visigodo", cuida de nos mostrar como Isidoro de Sevilha influenciou reis e teve participação política enorme. Quanto à característica, suas obras eram trajadas por uma cultura clássica como forma, e a patrística, como conteúdo, sendo basilares por séculos e um modo de difusão do saber clássico no medievo. Nessa lógica, Feldman entende que o intento de Isidoro foi formar monges e padres, influenciar reis e nobreza, elevar o saber cristão.

Para isso, recorreu a muitos outros autores. Feldman o defende das acusações de plágio com a afirmativa da necessidade de compreender as palavras para apreender a obra. Assim, destaca que a metodologia medieval era prestar atenção à etimologia. A obra de Isidoro expõe um panorama da época e se preocupa com a linguagem, sempre com a máxima de compreender o sentido das palavras, o que estava ligado à exegese dos textos sagrados. Feldman afirma que Isidoro se utiliza da gramática para propagar a fé.

As obras de Isidoro apresentam o caráter de preparar o mundo cristão para o reino de Deus. No entanto, ele defrontou com a herança judaica nas escrituras, e uma das formas foi tecer novas interpretações e desqualificar a leitura judaica. Nesse processo, o bispo de Sevilha forrou suas obras com uma leitura alegórica do texto sagrado. Tendo percebido essa prática, Feldman desvelou suas artimanhas discursivas e percebeu nas entrelinhas a justificação da deslegitimação judaica.

Sem dúvidas, a presente obra nos permite compreender que os judeus representaram um grande desafio para a unidade religiosa, como atestam as fontes hispano-visigodas. Para isso, inserir o judeu, depois de convertido, garantiria a unidade almejada, e Isidoro foi o "motor" da política de conversões. Seguindo essa esteira interpretativa, Feldman concentra sua atenção nas obras De differentiae, Liber prooemiorum, De ortu e Allegoriae.

A primeira delas, tendo como objetivo entender o mundo e a história sob uma ótica específica, transforma os conteúdos enigmáticos do texto sagrado compreensíveis para clérigos e leigos. A segunda é um compilado de textos introdutórios aos livros bíblicos e talvez faça parte de um projeto inconcluso de Isidoro. O bispo busca uma síntese dos ensinamentos cristãos a fim de manter viva a cultura, combater o analfabetismo e a ignorância dos clérigos. Na terceira, Isidoro busca descaracterizar o direito dos hebreus/judeus da herança do pacto. Por fim, na quarta, temos uma coletânea de explicações de nomes de personalidades bíblicas com base em citações alegóricas ou simbólicas. Nessa obra, convergem tradições exegéticas greco-romanas, judaicas e cristã.

A leitura patrística, e de maneira específica a leitura isidoriana do texto sagrado, se torna uma referência fundamental para compreender e orientar o mundo presente, o cotidiano, a política e as relações entre os fiéis e com os infiéis e heréticos [...] os judeus são muito importantes na exegese pelo fato de terem sido os receptores iniciais das sagradas escrituras e, portanto, 
reivindicam seu direito e sua verdade na interpretação das mesmas. Isidoro trata de negar este pretenso direito à herança sagrada. Trata de criticar os judeus de maneira direta ou indireta em quase todos os temas (FELDMAN, 2017, p. 189).

Além da análise dessas obras e evidenciado o intento de Isidoro, Feldman se debruça sob Livro das sentenças e na polêmica obra De fide catholica. A primeira é entendida como a maior obra de Isidoro, tendo o pecado como eixo central e o alinhamento da sociedade com base na lei divina. Não é uma obra de exegese propriamente dita, mas carrega a análise do texto bíblico e moralidade. Isidoro entende o mundo permeado pela luta entre bem e mal. Seguindo a concepção de Agostinho de Hipona de que o pecado original tornou o homem suscetível ao pecado, Isidoro adota essa perspectiva que ocupa boa parte de seus escritos.

Germano Esteves elucida a atenção do bispo de Sevilha sobre o Diabo, uma vez que este se apresenta de forma sedutora aos justos, tentando enganá-los e levá-los à soberba, renegando toda a fonte de luz. Feldman contribui para essa discussão sobre a diabologia em Isidoro, demonstrando como isso é logo associado aos judeus e à sua "equivocada" interpretação da palavra de Deus, além da ligação entre sinagoga e os ensinamentos contra a Igreja. As associações do Diabo aos judeus são corriqueiras nas obras de Isidoro, bem como a acusação de que os judeus realizam uma leitura carnal dos textos sagrados.

A segunda obra, por sua vez, é conhecida pela questão antijudaica nela empregada, e Feldman a reconhece como fruto da exegese isidoriana. São tratados assuntos como a circuncisão, a desconstrução do pacto selado com Abraão e seus descentes, o significado do templo de Jerusalém, a negação do Shabat, o esforço de Isidoro pelo desmantelamento da identidade judaica, normas alimentares e, por fim, a culpa judaica na morte de Cristo. Isidoro também enxerga a maldade dos profetas. Dessa forma, acaba justificando a punição e as ações radicais contra os judeus.

O quarto e último capítulo, "Isidoro de Sevilha: identidade e unidade político-religiosa do reino visigótico", tem como objetivo compreender como Isidoro enxergou a história e o ideal de monarca cristão por ele traçado. Para tal fim, Feldman analisa algumas obras históricas de Isidoro: Crônica, História e De viris. Elas retratam o projeto isidoriano de constituir uma história do mundo e inserir os visigodos e a Hispânia nela, ainda que o objetivo fosse a legitimação do reino.

$\mathrm{O}$ autor defende que Isidoro de Sevilha manteve uma unidade de pensamento em todos os seus trabalhos, e isso pode ser explicado à luz de oferecer reflexões aos clérigos e letrados hispânicos. O modelo de monarquia e de monarca é aquele que cumprir seu papel na história: proteção e respeito à fé cristã, solidificando o pilar Império-Igreja. Feldman argumenta que o momento histórico favoreceu uma nova construção de monarca e a visão alegórica de Isidoro sobre a Hispânia ser uma formosa mãe e fecunda, transparecendo seu projeto de unidade político-religiosa.

Isidoro ressalta Leovigildo como um modelo monárquico e Recaredo e Suintila como exemplos, já que dão continuidade ao projeto de unidade. Ele se ocupa defendendo Recaredo e alicerçando sua glória. Feldman entende a relação política de Isidoro com os monarcas, mostra a figura de Isidoro como líder dos concílios e tecendo considerações aos monarcas, bem como suas ações diante da unidade política e interferências na Igreja. Ele modelou um ideal político. O autor demonstra a contradição sobre Suintila, ora como pai dos pobres, ora como confiscador de seus bens. 
Em sua construção de modelo de rei, adapta o conceito de virtudes reais de Martinho de Braga, separando virtudes reais das militares. A sucessão do rei é um tema controverso, haja vista que Isidoro e a Igreja flutuam de acordo com as necessidades do período. Feldman analisa que Isidoro não era contra a sucessão dinástica nem total adepto da eleição de sucessão dos reis por meio de um colegiado de nobres e alto clero, posto que, se assim fosse, esse termo apareceria mais vezes em seus escritos e no modelo real. $O$ autor parte da definição etimológica de rei e reino isidoriana; discorre sobre o rei justo e o rei mau.

Feldman destaca um ponto de contrassenso em Isidoro: a justificativa sobre o porquê haver rei num mundo em que todos são iguais. O castigo pela servidão, acarretada pelo pecado original, é contraditório, haja vista a doutrina do batismo. Todavia, Isidoro toma o batismo como ponto de partida em sua teoria de poder e altera a visão de rei advinda do baixo Império para seu conceito de monarquia cristã, ou seja, substitui o Império pela Igreja, passando as várias células a fazerem parte do reino de Cristo. Feldman entende uma razão religiosa para essas mudanças: judeus e arianos negavam a validade da trindade.

A teologia de Isidoro é cristológica. Ele não era monarquista, e sim realista, e estava cercado de reis; portanto, inserir esses na cristandade e fazê-los parte do plano divino era o objetivo. Feldman defende que a doutrina política advém do fundamento religioso. Menciona a função da unção real visigoda: legitimar os reis e impedir golpes de Estado e regicídios. Essa visão de Isidoro não é apenas sobre sua concepção de monarquia, mas também a forma como concebia o período histórico.

Arrematando suas reflexões, Sergio Feldman frisa que o pensamento isidoriano foi capaz de perceber as necessidades da cristandade, moldar um projeto político-religioso de sociedade e executá-los à luz de um combate excludente da comunidade judaica. Portanto, Isidoro de Sevilha nos oferece uma compreensão ampla acerca da Hispânia visigoda, e o livro aqui resenhado é um esforço interpretativo sobre essas abstrações do bispo de Sevilha. É também um exemplo de como a literatura patrística nos permite compreender a cosmovisão do homem daquele período, sobretudo se as considerarmos capazes de trabalhar com um conceito temporal assentado no mítico, em realidades só demonstráveis por símbolos, representações e alegorias.

Nesse caso, permitiu compreender o reino visigodo de Toledo, uma vez que, ao refletir sobre as entrelinhas dos escritos do bispo e perceber artimanhas e armadilhas de sua exegese a Feldman, engendrou entendimentos valiosos para um período histórico marcado por disputas políticas e religiosas.

\section{REFERÊNCIAS}

ANDRADE FILHO, Ruy de Oliveira. Imagem e reflexo: religiosidade e monarquia no reino visigodo de Toledo (Séculos VI e VII). São Paulo: Edusp, 2012.

ESTEVES, Germano M. F. Entre santos e demônios: a percepção do mal na teologia e hagiografias do Reino Visigodo de Toledo (séculos VI-VII). 266 f. Tese (Doutorado em História) - Faculdade de Ciência e Letras, Unesp, Assis, 2015.

FRIGHETTO, Renan. Cultura e poder na Antiguidade tardia ocidental. Curitiba: Juruá, 2000. 


\section{NOTAS}

\section{AUTORIA}

José Walter Cracco Junior: Graduado. Mestrando, Universidade Estadual Paulista Júlio de Mesquita Filho, Faculdade de Ciências e Letras de Assis, Departamento de História, Assis, SP, Brasil.

\section{ENDEREÇO PARA CORRESPONDÊNCIA}

Av. Dom Antonio, 2100, 19806-900, Assis, SP, Brasil.

\section{FINANCIAMENTO}

Não se aplica.

\section{APROVAÇÃO DE COMITÊ DE ÉTICA EM PESQUISA}

Não se aplica.

\section{CONFLITO DE INTERESSES}

Não houve conflito de interesses.

\section{LICENÇA DE USO}

Este artigo está licenciado sob a Licença Creative Commons CC-BY. Com essa licença você pode compartilhar, adaptar, criar para qualquer fim, desde que atribua a autoria da obra.

\section{PUBLISHER}

Universidade Federal de Santa Catarina. Programa de Pós-Graduação em História. Portal de Periódicos UFSC. As ideias expressadas neste artigo são de responsabilidade de seus autores, não representando, necessariamente, a opinião dos editores ou da universidade.

\section{EDITORES}

Alex Degan

Beatriz Mamigonian

Fábio Augusto Morales

Flávia Florentino Varella (Editora-chefe)

Tiago Kramer de Oliveira

Waldomiro Lourenço da Silva Júnior

\section{HISTÓRICO}

Recebido em: 14 de julho de 2019

Aprovado em: 06 de setembro de 2019

Como citar: CRACCO JUNIOR, José Walter. A unidade político-religiosa e a questão judaica na ótica de Isidoro de Sevilha. Esboços, Florianópolis, v. 26, n. 43, p. 636-642, set./dez. 2019. [Seção] Resenha. Resenha da obra de: FELDMAN, Sergio Alberto. As obras de Isidoro de Sevilha e a questão judaica: perspectivas da unidade político-religiosa no reino hispano visigodo de Toledo. Curitiba: Prismas, 2017. 308p. 